\title{
ANÁLISE DA IDEOLOGIA EVANGÉLICA CONSERVADORA DO PASTOR SILAS MALAFAIA EM RELAÇÃO À ABORDAGENS SOBRE IDEOLOGIA DE GÊNERO PELA DISNEY EM SEUS DESENHOS
}

\author{
Analysis of the evangelical ideology of the pastor Silas Malafaia in relation to the
}

approaches to ideology of gender by Disney in its drawings

\author{
João Borges da Silva ${ }^{1}$ \\ Juscelino Francisco do Nascimento ${ }^{2}$
}

RESUMO: O crescimento da população evangélica no Brasil e sua influência no meio social leva a desenvolver questionamentos de como se configura as suas posturas ideológicas diante de algumas temáticas em vigor na sociedade, principalmente, questões voltadas ao liberalismo sexual, como o homossexualismo, bem como, a ideologia de gênero. Analisamos como se dá a formação de lideranças para tais grupos, e como o posicionamento das mesmas influencia o grupo, como também, a sociedade. O trabalho também buscou observar o embate ideológico entre a classe liberal e a classe conservadora em questões que tangem a ideologia de gênero. Vale lembrar que a base de análise do discurso do pastor Silas Malafaia foi um vídeo retirado da internet. Alguns teóricos foram cruciais no desenvolvimento deste trabalho, podemos destacar Bakhtin (2009), Brandão (2006a; 2006b), Pêcheux (2014), os quais nos ajudaram a percebemos a existência de um grande embate ideológico, em que cada discurso tenta prevalecer sobre o outro, buscando visibilidade. Porém, no âmbito analisado não houve vencedores, apenas pessoas com ideologias diferentes, que precisam ser respeitadas por ambas as partes.

Palavras-chave: Evangélicos. Ideologia. Discurso. Gênero.

ABSTRACT: The growth of the evangelical population in Brazil and its influence in the social environment leads to the questioning of how its ideological positions are configured in the face of certain issues in society, especially issues related to sexual liberalism such as homosexuality, as well as the ideology of genre. We analyze the formation of leaderships for such groups, and how their position influences the group, as well as society. The work also sought to observe the ideological clash between the liberal class and the conservative class on issues that affect gender ideology. It is worth remembering that the basis of analysis of pastor Silas Malafaia's speech was a

${ }^{1}$ Graduando em Letras - Português e Literatura de Língua Portuguesa da Universidade Federal do Piauí, Campus Senador Helvídio Nunes de Barros. E-mail: joao_borges_65@hotmail.com

2 Doutorando em Linguística da Universidade de Brasília (UnB). Professor Assistente I da Universidade Federal do Piauí, Campus Senador Helvídio Nunes de Barros. E-mail: juscelinosampa@hotmail.com

Cadernos Cajuína, V. 4, N. 1, 2019, p.232 - 246.

ISSN: 2448-0916 
video taken from the internet. Some theorists were crucial in the development of this work, we can highlight Bakhtin (2009), Brandão (2006a; 2006b), Pêcheux (2014), which helped us to perceive the existence of a great ideological clash, in which each discourse tries to prevail over the other, seeking visibility. However, in the scope analyzed there were no winners, only people with different ideologies, who need to be respected by both parties.

Keywords: Evangelicals. Ideology. Speech. Genre.

\section{CONSIDERAÇÕES INICIAIS}

As ideologias trazem marcas grupais, que em si definem o comportamento cultural e social de seus membros, assim, conhecer suas ideologias é conhecer crenças, raízes e, até mesmo, entender como e porque se dá tal conduta. Apesar do Brasil ser conhecido no exterior como o país das diferenças religiosas, ele pode ser considerado uma nação majoritariamente cristã, uma vez que a população que se declara seguidora de tal segmento religioso, segundo o Instituto Brasileiro de Geografia e Estatística (IBGE), correspondia a cerca de 87\% da população em 2010, ano em que se realizou o último censo. Sendo que, desse total, o segmento católico se sobressai. A grande maioria dos brasileiros se declararam católicos, cerca de $64,6 \%$ da população total do país. Apesar de ainda ser maioria da população, essa porcentagem é a menor, desde que o IBGE começou a registrar tais dados.

O percentual da população que se declarou evangélica nesse período, correspondia a $22,2 \%$ do percentual total da população brasileira. É importante salientar que, ainda segundo o IBGE, tal segmento é o que mais cresce no país nos dias atuais. O grupo tem ganhado bastante espaço na educação, na política, nas artes, enfim, em todos os segmentos da sociedade. Apesar de ser um fenômeno novo, o crescimento da religião evangélica se dá de forma constante em todos os setores da sociedade, ou seja, o seu crescimento ocorre de maneira homogênea em todas as classes sociais.

Andrade (2010, p. 19) afirma que, "nos últimos anos o fenômeno religioso adquiriu novos aspectos, se revelando um fenômeno complexo, plural, multifacetado e inter-relacionado com o contexto social no qual se insere", assim, em amplo contexto, percebe-se a grande "reviravolta" religiosa que acontece no Brasil. Porém, é importante ressaltar, que esse percentual inclui todos os ramos protestantes em 
exercício no país, onde apesar das diferenças doutrinárias, tem como base principal a mesma fé - a Bíblia como única regra de fé e prática, proibição de imagens durante os cultos de adoração, todas creem no sacrifício de Jesus, enfim, possuem uma mesma formação ideológica. Nas palavras de Brandão (2006b, p. 06), formação ideológica diz respeito a:

Um conjunto de atitudes e representações que os falantes tem sobre si mesmos e sobre o interlocutor e o assunto em pauta. Essas atitudes e representações estão relacionadas com a posição social de onde falam ou escrevem, com as relações de poder (muitas vezes contraditórias, conflituosas) que se estabelecem entre eles.

Com base em tal afirmação, apesar de estar dividido em várias vertentes histórica, pentecostal e neopentecostal -, possuindo vários pontos de vistas, os quais podem perfeitamente ser agrupados em uma mesma formação ideológica. Quando o assunto diz respeito à questões voltadas ao aborto, o sexo fora de um contexto de marido e esposa, a pornografia, e, principalmente, a homossexualidade, ambos os segmentos posicionam-se rigorosamente contrários a tais práticas. Não é novidade que os demais membros da sociedade, não raramente, taxam o grupo de radicais e de extremamente conservadores. Apesar de haver várias dissenções doutrinárias entre uma ou outra denominação eclesiástica, as semelhanças entre eles são notáveis. Eles estão amparados por uma mesma fé, o que os diferencia é o modo como colocam em prática suas crenças, uns mais radicais, outros mais conservadores. Mas, no geral, ambos seguem uma mesma linhagem de pensamento. Como nos diz Souza (2013, p. 181-182):

O conservadorismo atribuído a esses grupos demanda alguma relativização, uma vez que eles são bastante permeáveis às mudanças, tendo abandonado a postura ascética. Outros segmentos religiosos, cristãos e não cristãos, também poderiam ser analisados nessa perspectiva, mas os pentecostais e neopentecostais no Brasil destacam-se nesse quesito, por exemplo, na formação de lideranças para atuarem nas igrejas e fora delas.

Encontramos então, uma confirmação do que se havia explicitado anteriormente, pois observamos uma mesma conduta regendo esse grupo, fortes fatores conservadores que o permeiam. Porém, entendemos que assim como em qualquer outro grupo religioso ou social, as mudanças são inerentes. Todos estão 
suscetíveis às mesmas. Esse fator beneficia a necessidade do surgimento de algum líder para poder governar a igreja, fazer com que ela não perca o seu foco doutrinário. Sendo que, não raramente, as influências desses líderes transcendem as paredes do templo e passam também, a usar a sua influência para argumentar sobre questões da sociedade que são contrárias ou a favor das ideologias defendidas pelo grupo.

Nessa perspectiva, este trabalho se propõe a analisar as ideologias evangélicas presentes no discurso de um dos líderes evangélicos mais influentes na atualidade, o Pastor Silas Malafaia ${ }^{3}$, que assim como seu grupo, usa suas influências na sociedade para defender seu ponto de vista em relação às questões que marcham contra a fé protestante, principalmente, questões voltadas à ideologia de gênero, tão defendida por representantes homossexuais.

Vale lembrar que, a ideologia de gênero, defendida por tais representantes, pode ser entendida como ausência de sexo. Nela, se apregoa, que a criança nasce em um sexo "neutro", ou seja, sem sexualidade biológica e psicológica definida. Segundo essa visão, a questão de "ser homem" ou "ser mulher" é apenas uma mera convenção ideológica, que foi construída pela sociedade tradicional, principalmente através da influência judaico-cristã. $E$, neste sentido, a ideologia de gênero apregoa que a criança tem a liberdade de escolher o gênero que the convir, seja ele masculino ou feminino; já que, isso não vem predefinido no nascimento, mas deve ser orientada pela convivência e a posterior escolha, por parte da criança sobre o que deseja ser.

\section{IDEOLOGIA: O QUE É E COMO SE CONSTRÓI?}

O conceito de ideologia está relacionado ao de discurso, pois, é através deste que a ideologia se concretiza. Diante disso, se faz necessário compreendermos que o discurso, de acordo com Brandão (2006b), diz respeito a toda e qualquer atividade comunicativa que se estabeleça entre interlocutores e que detenham sentidos, significações durante o processo de comunicação dos mesmos. Sendo conveniente ressaltar, que o ato discursivo não se refere apenas à produção

\footnotetext{
${ }^{3}$ Silas Lima Malafaia, popularmente conhecido como Pastor Silas Malafaia, é um pastor pentecostal brasileiro, líder do movimento Vitória em Cristo, ligado às Assembleias de Deus.
} 
verbal, mas também, a práticas não verbais que são detentoras de um significado, de uma ideologia.

Percebemos então, que o conceito de ideologia está ligado de modo intrínseco a questões culturais e sociais de uma determinada sociedade ou grupo social, que ao produzir, ou mesmo, reproduzir algum discurso deixa transparecer as suas ideologias, seu modo de enxergar a realidade que o cerca. É necessário compreendermos que, para que um discurso se concretize faz-se necessário a existência de um sujeito ideológico.

De acordo com Pêcheux (2014, p. 145) o sujeito se consolida na língua por meio da utilização do discurso por um indivíduo, quando ele realmente se apropria de conceitos para então, formular o seu próprio conceito. Nesse sentido, podemos perceber que umas das condições essenciais para a existência de um sujeito no discurso está relacionada à presença da subjetividade, a partir do momento em que o mesmo deixa ser um mero receptor e passa a reproduzir suas opiniões, seu posicionamento, em outras palavras, suas ideologias.

É importante destacar que, ainda de acordo com Pêcheux (2014), um sujeito jamais será passivo ao reproduzir algum discurso, uma vez que ele sempre estará repleto de suas ideologias. Nisto, todo sujeito estará enquadrado em alguma formação discursiva - diz respeito às suas próprias opiniões - que, certamente estará relacionada a alguma formação ideológica, que faz menção às características gerais das ideologias comportadas em determinado grupo social. Nesse contexto, a ideologia é compreendida como um modo de ver, próprio de um determinado grupo ou classe, podendo também, ser definida como um sistema de crenças, um conjunto de ideias que utilizam como estrutura de sustentação, posições políticas, religiosas, culturais ou econômicas.

Essas ideologias presentes no discurso funcionam como uma forma de o sujeito "agir" sobre o receptor, pois o mesmo é induzido, geralmente, de forma implícita, a respeito da argumentação exposta pelo sujeito falante. Sendo assim, podemos observar que o sujeito jamais faz uso da neutralidade no seu discurso, visto que ele é altamente ativo, na tentativa de convencer o receptor de que sua posição é certamente a correta. E para tal, faz uso de argumentações em uma tentativa de comprovar sua posição. Essa regra se aplica a todos os discursos, inclusive o discurso religioso, o qual nos propomos analisar ao longo deste trabalho. 
Assim, temos um campo de análise bastante complexo onde, por traz de um aparente discurso, existe um vasto campo de ideologias a serem analisadas, ideologias que estão implícitas no discurso do referido pastor, e, consequentemente, no seu rebanho. O discurso analisado faz referência a um pronunciamento do sujeito-falante (pastor Silas Malafaia) para a sociedade em si - especialmente os evangélicos - (receptores), através de um vídeo em circulação na internet, no qual critica a questão das abordagens da empresa cinematográfica americana - Wal Disney ${ }^{4}$ - sobre a ideologia de gênero nos desenhos infantis por ela produzidos e distribuídos mundialmente, inclusive no Brasil.

\section{CONSERVADORISMO VERSUS LIBERALISMO}

O mundo atual passa por um processo de globalização em que as mudanças são cada vez mais constantes e é inegável que as mudanças ideológicas não são resultados apenas de mudanças de comportamento, muito mais do que isso, são mudanças na forma como o ser humano enxerga a realidade ao seu redor. Nesse contexto, o processo que nomeia essas transformações na sociedade como um todo é conhecido como secularização. Isso quer dizer que o pensamento humano, bem como seu comportamento, no processo de secularização, não aceita os dogmas religiosos predefinidos, mas que se baseia em argumentos empiristas e científicos para pôr sobre a base de suas crenças.

Em controvérsia a isso, o conservadorismo visa à preservação das estruturas sociais já estabelecidas por gerações passadas, alegando que, caso sofram repentinas e constantes mudanças, ocorrerá um súbito desequilíbrio social, já que todo sistema possui regras de funcionamento preestabelecidas, que não podem ser violadas. Pode-se afirmar que, uma das responsáveis pela permanência do conservadorismo na sociedade moderna, se não a responsável, é a religiosidade. Ela constitui um "esqueleto" que dá sustentação a tal configuração ideológica, pois, a própria religião constitui uma das origens de tal discurso.

No contexto analisado, as questões referentes às mudanças ideológicas estruturais na sociedade, quanto a referenciação do que é ser o gênero feminino e o que é ser o gênero masculino e a defesa de um gênero neutro por alguns grupos

\footnotetext{
${ }^{4}$ The Walt Disney Company é uma multinacional Estadunidense no ramo do entretenimento de massas, fundada em 1923 pelos seus fundadores, Walt Disney e Roy Oliver Disney.
}

Cadernos Cajuína, V. 4, N. 1, 2019, p.232 - 246.

ISSN: 2448-0916 
LGBTs e políticos, constitui uma vertente liberalista, onde existe uma tentativa de "libertar-se" totalmente dos resquícios que ficaram do estado religioso que perduram até hoje. E, da mesma maneira, o ataque a esse sistema, o combate a tais ideologias, advindo de grupos religiosos, constitui uma forte corrente de resistência conservadorista, que tenta preservar os valores e as tradições judaico-cristãs, que serviram de base para a formação discursiva e ideológica no país. Souza (2013) argumenta que apesar de serem conservadores, esse grupo também é suscetível à mudanças, pois também, busca estar se atualizando, sendo visíveis às mudanças de posturas que as denominações sofreram ao longo das últimas décadas, deixando de serem imparciais com as questões seculares e sociais e agora, investindo na formação de lideranças para representarem a igreja dentro e fora delas.

Nisso, percebemos que a formação de líderes religiosos influentes constitui uma forma pela qual os evangélicos fazem uso para expandirem suas influências na sociedade. Esses líderes têm um importante papel na manutenção e propagação das ideologias evangélicas, pois "a ovelha constitui um retrato do seu pastor", já diz um ditado popularmente conhecido no meio; comprovando-se então, a tese anteriormente defendida, de que um líder influencia fortemente na formação ideológica de seus fiéis e não somente dentro da igreja, mas, por estar à frente de um grande número de pessoas, um líder religioso constitui indiretamente um líder político, e assim, passa a influenciar toda sociedade com seus ideais.

É justamente de fatos assim, que se estabelece esse embate ideológico entre os ideais liberais, fortemente defendidos pelos seus representantes, sejam eles, grupos LGBTs, feministas, ateus etc., que tentam usar a influência de seu grupo para influenciar na criação de leis que congratulem com seus ideais; e, os ideais conservadores, que, em suma, são defendidos pelo segmento religioso da população, semelhante forma, tentam fazer uso do poder social contido no seu grupo para tentar fazer com que o conservadorismo seja mantido, papel esse desempenhado pelos líderes das instituições que possuem voz ativa na sociedade e são considerados "enviados de Deus" para defender o seu povo do processo de secularização social, visto com maus olhos pelo segmento evangélico.

\section{IGUALDADE SOCIAL OU DETURPAÇAO DE VALORES? O PENSAMENTO DE SILAS ANTE A ATITUDE DA DISNEY}


Em virtude da grande influência exercida pela parcela evangélica da população na educação, na política, na cultura, no entretenimento etc., torna-se necessário um estudo que avalie a configuração de tal corrente de pensamento. Assim, para entender o povo, nada melhor do que analisar os seus líderes, que podem ser considerados os organizadores de toda essa estrutura ideológica a qual se configura hoje. E, é para isso, que propomos a realização deste estudo, no qual analisamos o ponto de vista apresentado pelo pastor Silas Malafaia em relação à atitude da empresa de entretenimento infantil americana, famosa no mundo inteiro, Wall Disney, em lançar, em seus desenhos animados, algumas cenas um pouco "polemicas", que dizem respeito à questão da ideologia de gênero, tão defendida por representantes homossexuais.

Tal discurso está presente em um vídeo disponibilizado no YouTube. Importante ressaltar que, não há menção a data de sua gravação, já que ele foi compartilhado por inúmeros usuários do site, o que não deixa de ser verídico, pois, tais ideias, ainda correspondem ao contexto ideológico que circunda a vida do referido pastor. Assim, através da lente de algumas teorias que englobam a área da Análise do Discurso $(A D)$, analisaremos a influência ideológica cristã conservadora no pensamento do pastor e de semelhante forma, a influência das ideologias do líder religioso em seu grupo e na sociedade em si.

Já, desde o início do vídeo, podemos observar uma postura ideológica conservadora por parte do pastor, reflexo das ideologias do seu grupo ou vice-versa. Nisto, tendo em vista a sua influência na formação do pensamento de seus fiéis seguidores, o pastor inicia o vídeo especificando o público o qual se deseja alcançar referindo-se ao "povo abençoado do Brasil", ou seja, aos evangélicos como um todo, delimitando ainda mais, quais pessoas dentro desse grupo, deseja alcançar, através desse "alerta', que são, principalmente "as famílias e os pais". Através desse primeiro diálogo, podemos então, compreender que se tratará de um discurso que valorizará valores tradicionais cristãos, que regeram por muito tempo a sociedade, uma vez que temos o apego a uma graça sobrenatural, ligada à benção do criador sobre os que o temem e citam a principal base do pensamento conservador, a saber, a família.

A partir de então, o pastor faz uma série de declarações sobre o comportamento da empresa norte americana Disney, que refletem o seu pensamento em relação a empresa, "lamentavelmente a Disney resolveu comprar a 
'agenda gay' colocando em seus desenhos e filmes para crianças a questão do homossexualismo" diz Malafaia. Nesse breve trecho, já podemos compreender que rumos tomarão esse discurso, pois o mesmo é iniciado em um tom de lamento, de pesar, o que transmite para o público ouvinte a ideia que serão tradados fatos seríssimos; e, desde o início, em sua discussão, podemos enxergar uma tentativa, por parte do pastor, de trazer o público para o lado de seus ideais, seus valores, pois a empresa está agindo de modo incoerente com sua função na fabricação do entretenimento.

O que podemos observar é que, na visão do pastor não se trata de um simples entretenimento, mas, de um programa tendencioso e ideológico. Nisto, a própria Disney institui-se como um sujeito, pois, segundo Pêcheux (2014), a presença da subjetividade é uma das marcas fundamentais que definem a presença de um sujeito discursivo que materializa as suas ideologias, através da utilização de um discurso por um indivíduo/empresa. Apesar dessa posição ideológica da empresa não estar explícita, ela se constrói de modo implícito no discurso dos personagens, como afirma o trecho a seguir, no qual Pêcheux (2014, p. 148) chega à conclusão que:

O próprio de toda formação discursiva é dissimular, na transparência do sentido que nela se forma, a objetividade material contraditória do interdiscurso (diálogos entre diferentes discursos), que determina essa formação discursiva como tal, objetividade material essa que reside no fato que "algo fala" sempre "antes em outro lugar e independentemente", isto é, sob a dominação do complexo das formações ideológicas.

Através desse, percebemos que toda formação discursiva, possui informações que são conhecidas, aquelas que estão explícitas, visíveis no discurso, bem como também, é portadora de informações implícitas, aquelas que não estão visíveis, entrando então, a questão das interpelações. Então, no âmbito do discurso da Disney, vale ressaltar que esse discurso, assim como os demais, não é algo passivo, pelo contrário, é ativo, devido a uma tentativa de repassar seus ideais liberais e, para isso, utiliza determinados mecanismos ideológicos de dominação, que estão estruturados de acordo com a visão que possui sobre a sociedade.

Se é impossível um sujeito não fazer menção de sua posição ideológica no discurso que domina, pois este depende daquela para se instituir, Malafaia também 
deixa explicito os seus ideais, por ser autor de seu próprio discurso. Vale lembrar que, o pastor teve outros discursos como base, pois, na concepção de Bakhtin (2009), um discurso sempre estará relacionado a outros discursos, mas, a partir do momento em que o sujeito se apropria de discursos anteriores, cria assim, o seu próprio discurso, então, apresenta-se como sujeito. É a partir da bíblia que os cristãos, no caso os evangélicos, tiram as bases de suas crenças, e por se tratar de um livro sagrado para os seguidores desse segmento, concluímos previamente que, as ideologias conservadoras do líder religioso têm em sua primazia, o discurso bíblico; que segundo os cristãos, é de autoria inspirada pelo próprio Criador, que constitui o seu sujeito. E nisso se supõe, que a posição ideológica apresentada pelo líder ante às questões homoafetivas e seculares em si, compara-se à posição defendida pela Bíblia, que em sua religiosidade vai totalmente contra tais parâmetros. Entrando a questão do interdiscurso, definido por Brandão (2006a, p. 26) como:

A relação de diálogo que um discurso trava com outros discursos: todo discurso nasce de um trabalho sobre outros discursos, isto é, ao falar citamos, discutimos polemizamos com outros discursos situados no presente ou no passado. A interdiscursividade é própria de todo discurso e é consequência do princípio do dialogismo que caracteriza a linguagem humana.

No momento em que o referido pastor usa o seu discurso para dialogar como o discurso bíblico, estabelece-se um interdiscurso, que, como afirmou Brandão (2006a), é algo inerente a todos os discursos, visto que sempre há alguma inferência ou referência a outro discurso. E nisso, em concordância com os ideais bíblicos, Malafaia vê a atitude da Disney como algo agressivo à educação sexual da criança brasileira e explicita em seu discurso que: "Não tem coisa mais asquerosa, mais nojenta, do que erotizar crianças! A criança, ela não sabe discernir o que é ordenança, informação e sugestão. É uma covardia pular etapas no desenvolvimento do ser humano". Nesse trecho, o pastor traz alguns conhecimentos do ramo da Psicologia, utilizando-os para fundamentar e dar ênfase a sua tese. Essa suposta "erotização de crianças" estava presente em alguns desenhos da empresa que circulam no Brasil, porém, o vídeo não revela o nome do desenho animado, talvez, em uma tentativa de relacionar tal acontecimento aos demais desenhos produzidos pela companhia. 
Em virtude de todas as circunstancias, liberais não se conformam com a atitude do pastor e saem em defesa da companhia, argumentando que é necessário quebrar os "tabus" que ainda persistem em nossa sociedade, defendendo o livre acesso de todos a essas questões, para que, desde criança, se tenha consciência dos fatos como "normais", evitando assim, a tematização do preconceito. Em contra resposta, o pastor argumenta que a criança não tem idade mental para discernir se o que está sendo repassado é uma ordenança, sugestão de comportamento ou apenas mais uma informação, o que induziria a um comportamento ideológico inadequado. Para fundamentar tal opinião, Silas faz uso de uma série de fontes, para mostrar que tal atitude vai contra as leis e regimentos que envolvem a criança no Brasil e no mundo. Vejamos a seguir um trecho do seu discurso que fundamenta esses argumentos.

Ensinar sexualidade à criança é a coisa mais covarde que tem! Tanto é que o artigo 229 da constituição federal diz que a educação pertence aos pais, o Brasil é signatário da convenção Americana de direitos humanos que no artigo 12 diz que pertence aos pais a educação moral e religiosa. A declaração universal dos direitos humanos no artigo 26 e inciso 3, pertence aos pais a questão do ensino da sexualidade e o estatuto da criança e do adolescente tem vários artigos proibindo mostrar cenas de indução a sexo para as crianças e tem acordo no STJ proibindo isso em livros e em qualquer tipo de publicação. Onde é que iremos parar? (SILAS MALAFAIA)

Podemos chegar à conclusão que, tendo em vista que se o pastor Silas fizesse uso apenas de um discurso pautado em questões bíblicas, não obteria sucesso em seus artifícios discursivos, ele faz uso de declarações constitucionais, consideradas as bases da justiça brasileira. Por meio disso, ele reforça a questão da credibilidade do seu ato discursivo, pois tenta repassar a ideia de que seus ideais não são motivados apenas por questões e argumentos religiosos, pois as próprias leis do país, são postas, no presente discurso, como base sólida de suas crenças. $\mathrm{Na}$ verdade, isso constitui uma sábia e importante manobra, pois, se estamos em um país laico, o que está escrito em um livro religioso utilizado em determinado segmento não tem o mesmo valor, às vezes valor nenhum, em outro segmento ideológico religioso; ao contrário de documentos oficiais da nação e, até mesmo, de documentos de organizações internacionais que abrangem não só um segmento religioso, mas todos os cidadãos que, porventura, estiverem situados na área de abrangência de tais documentos. 
Ainda percebemos o inconformismo do pastor, ante os conceitos emitidos pelos opositores, tanto é que continua a tentativa de aliar conhecimentos religiosos a conhecimentos científicos. Podemos afirmar isso, ao ver 0 argumento que "homossexualismo é comportamento, e a maior prova disso é que o ativismo gay que vivia dizendo que o camarada nasce homossexual agora fizeram 'opção' pela ideologia de gênero". Inicialmente, usa novamente a Psicologia como tentativa de apoio ao seu discurso. Ao afirmar que homossexualismo é um comportamento, há uma tentativa implícita de relacionar que as crianças, que são os alvos de consumo de tais produtos, estariam suscetíveis a desenvolver tal comportamento, já que não saberiam discernir sobre o que está acontecendo, como falado anteriormente, acabariam por ver aquela atitude como 'normal' e que não teria problema algum praticá-la. E isso seria um problema, tendo em vista, as posições ideológicas conservadoras, mencionadas pelo pastor e seu grupo.

Ainda percebemos, uma tentativa por parte do pastor, de dizer que os grupos LGBTs são incoerentes em seus discursos, pois anteriormente, afirmavam que o ser homossexual já 'nascia gay' e não 'tornava-se gay'; como está implícito na questão da ideologia de gênero, quando esta afirma que todos os seres humanos são neutros, quanto à sexualidade, ao nascer, e, a partir da convivência é que vai ser escolhido qual sexo a criança quer ser. Se analisarmos, há um choque implícito de conceitos. Segundo o pastor, é apenas mais uma 'ideologia', não é ciência e afirma que: "eu só conheço o gênero humano, eu não conheço o gênero masculino e feminino, eu conheço biologicamente masculino e feminino... gênero masculino e feminino só se for na gramática."

Em consonância com os fatos apresentados, Silas usa sua influência para convocar a população evangélica a se posicionar contra essa postura da Companhia: "a Disney tem o direito dessa aberração e nós temos o direito de combater isso!'. Um ponto importante de ser salientado é que a liderança evangélica se assemelha a uma estrutura patriarcal, na qual o líder, assim como a figura paterna, tem o dever de 'proteger' os seus dependentes contra circunstâncias que porventura surgirem para pôr em desordem uma estruturação que há milênios foi instituída. O líder é visto como um enviado de Deus para ajudar o povo. E para que isso aconteça, Malafaia convoca todos os cristãos praticantes - Católicos e evangélicos -, que constituem a maioria da população brasileira, para posicionaremse contrários a esse fato. Veja a continuação do seu discurso abaixo: 
No Brasil, católicos e evangélicos praticantes são mais de $50 \%$ da população. Vamos dizer não a Disney. Não compre produtos da Disney para seus filhos! Cancele canais da Disney! Essa é a resposta democrática que podemos dar a estes que querem deturpar a criança, erotizando a criança para uma das coisas mais incríveis do ser humano que demora quase 21 anos para ser formada que é o impulso. Nós não podemos aceitar isso. Pais, o que está em jogo é o futuro dos seus filhos, VAMOS DIZER NÃO À DISNEY!" (SILAS MALAFAIA)

Observamos que o discurso do referido líder religioso é um discurso estritamente conservador, baseado em uma tipologia bíblica do que é ser um cristão verdadeiro; e, para se alcançar tal parâmetro, o pastor deixa claro, que é necessário andar na contra mão de tudo aquilo que vai contra as ideologias defendias pela igreja, deixando implícito que essas mudanças não dizem respeito à questões de igualdades sociais, religiosas e sexuais, mas, pelo contrário, constituem uma afronta para a concretização dessa igualdade, pois vai contra os princípios morais da grande maioria dos brasileiros. Como grande líder religioso, reconhecido internacionalmente, Silas Malafaia se vê no dever, de convocar os seus fiéis, de usar a sua influência para convidar todos os cristãos praticantes a posicionarem-se contrários a essa prática. Uma verdadeira guerra travada entre conservadores e liberais.

\section{CONSIDERAÇÕES FINAIS}

Muitos são os embates filosóficos que são instituídos diariamente, relacionados à questões de cunho religioso ou mesmo, não religioso, e como podemos observar, o Brasil é um pais onde há uma grande quantidade de culturas que convivem mutualmente, formando a pátria. Um país multifacetado, miscigenado pela grande quantidade de povos que o fecundaram e deram origem a configuração política e ideológica que conhecemos. Tendo em vista esses fatos, a religião deriva como algo peculiar na formação cultural e na postura ideológica de uma nação, não somente uma, mas as religiões, ou mesmo, a ausência delas, no caso dos ateus.

Dentro desse universo religioso, a religião evangélica merece certo destaque, não por ser melhor ou pior do que as demais, mas pelo fato de ser 0 grupo religioso de maior crescimento e de notória participação na política e nas 
questões de cunho moral e social. É inegável a influência de seus líderes não só no meio religioso, como também, fora dele, na sociedade em si. Assim, esse trabalho foi estabelecido, como uma tentativa de se aprofundar melhor nas questões em destaques na sociedade contemporânea, analisando o embate ideológico produzido pelas correntes conservadoras em relação às correntes liberais, utilizando para isso, o discurso do pastor Silas Malafaia, que comprovadamente, exerce grande influência no pensamento do grupo evangélico e também, fora dele.

Ficou-se comprovado, através da análise do discurso de tal líder, que existe uma forte divergência cultural entre os grupos analisados e que a atitude da Disney de realizar abordagens em seus desenhos sobre a tematização da ideologia de gêneros e questões homoafetivas em geral, é vista com maus olhos por esse grupo, que o entende como uma ofensa moral, ou mesmo religiosa, pois entende-se que esse segmento, apesar de estar suscetível à inovações e à mudanças na postura ideológica, ainda tenta conservar os valores tradicionais, em sua maioria, advindos do sistema judaico-cristão, que inegavelmente, ainda exerce uma forte influência na configuração ideológica do povo brasileiro.

Finalmente, Malafaia age de modo a induzir que, não somente a religião evangélica, que é vista como muito conservadora, como também, membros praticantes da religião católica, que como já explicitado, também é cristã, se posicionem contrários a tais práticas realizadas pela Disney. E assim, se estabelece esse embate entre conservadores e liberais, como já nos afirmava Brandão (2006b, p. 05): "o discurso é como uma arena de lutas em que locutores, vozes, falando de posições ideológicas, sociais e culturais diferentes procuram interagir e atuar um sobre o outro", ou seja, comprovamos esse fato, através deste trabalho. Ambos lutam em busca de maiores espaços de influência na sociedade, e, nesse embate ideológico, pelo menos no âmbito analisado, não há vencedores, apenas cidadãos com ideologias diferentes, que precisam respeitar o espaço do outro na sociedade.

\section{REFERÊNCIAS}

ANDRADE, Eliana Santos. A visão celular no governo dos 12: estratégias de crescimento, participação e conquista de espaços entre os batistas soteropolitanos de 1998 a 2008. 156 f. Dissertação (Mestrado em Ciências Sociais) - Faculdade de Filosofia e Ciências Humanas da UFBA, Salvador, 2010. 
BRANDÃO, Helena Hathsue Nagamine. Introdução à análise de discurso. 2. ed. Campinas: UNICAMP, 2006a.

Analisando o discurso. In: Ataliba Teixeira de Castilho. (Org.). Portal da Língua Portuguesa. São Paulo, SP; Fundação Roberto Marinho, 2006b, p. 1-30. Disponível em: http://www2.eca.usp.br/Ciencias.Linguagem/Brandao AnalisandoODiscurso.pdf $>$. Acesso em: 07 jun. 2017.

BAKHTIN, Mikhail (VOLOCHINOV, Valentin Nikolaevich). Marxismo e filosofia da linguagem. Tradução Michel Lahud e Yara Frateschi Vieira. 13. ed. São Paulo: Hucitec, 2009.

INSTITUTO BRASILEIRO DE GEOGRAFIA E ESTATÍSTICA (IBGE). Censo de 2010: As religiões no Brasil. Disponível em: < http://www.censo2010.ibge.gov.br/ > Acesso em: 15 jun. 2017.

MALAFAIA, Silas. Protesto: Disney quer erotizar crianças com homossexualismo. Disponível em: < https://www.youtube.com/watch?v=kcMd91V5gEk >. Acesso em: 15 jun. 2017.

PÊCHEUX, Michel. Semântica e discurso: uma crítica a afirmação do obvio. Tradução: Eni Puccinelli Orlandi et al. 5. ed. Campinas: Editora da Unicamp, 2014.

SOUZA, Sandra Duarte de. Política religiosa e religião política: os evangélicos e o uso político do sexo. Estudos de Religião, v. 27, n. 1 • 177-201 • jan.-jun. 2013. Disponível em: < https://www.metodista.br/revistas/revistasims/index.php/ER/article/view/4160/3622 > Acesso em: 31 mai. 2017. 